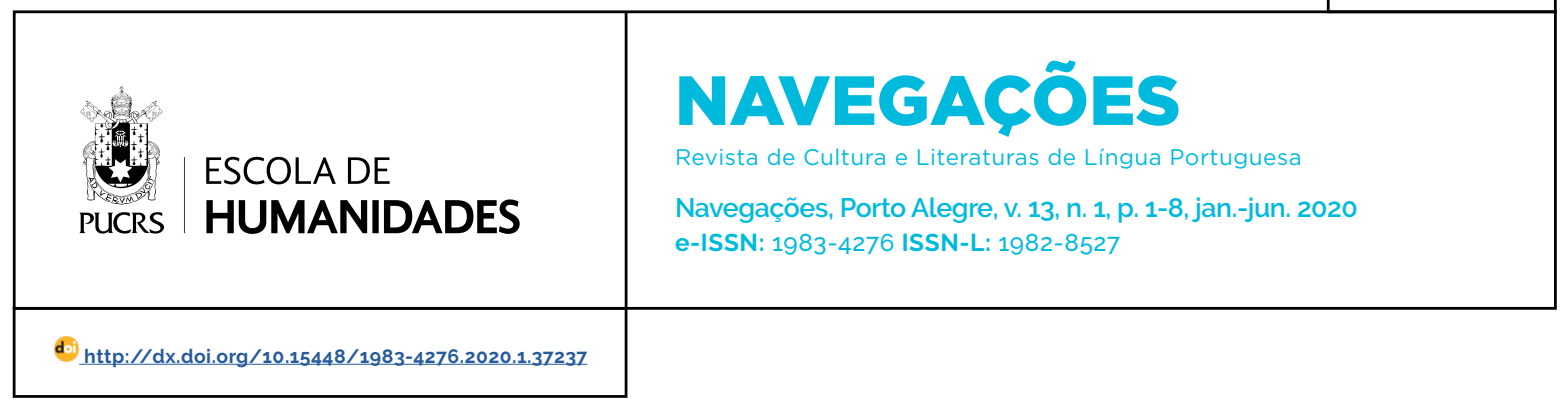

SEÇÃO: DOSSIÊ

\title{
A versificação do oriente através dos cantos cecilianos: uma breve imersão no Poemas escritos na Índia
}

\author{
The east's versification through Ceciclia Meireles' chants: a brief immersion in Poems \\ written in India
}

\section{Amanda Moury \\ Fernandes Bioni ${ }^{1}$ \\ orcid.org/0000-0002-2166-3706 \\ manda.m.f.bioni@gmail.com}

Recebido em: 6 mar. 2020

Aprovado em: 8 abr. 2020.

Publicado em: 10 ago. 2020.
Resumo: O presente artigo objetiva realizar uma leitura etnográfica de dois poemas intitulados, "Multidão" e "Pobreza", presentes no livro Poemas escritos na India (1961), pertencente à poeta brasileira Cecilia Meireles. Ao considerar a importância de compreender, olhar e dar voz ao outro nos contextos em que o egocentrismo impera, a empreitada etnográfica se assume como uma inadiável possibilidade. Com efeito, a escrita do deslocamento em tecido poético disponibiliza distintas versões e possibilidades de compreensão do universo estrangeiro, uma vez que a linguagem literária é plurissignificativa. Sobre esse aspecto, distintos personagens da cultura indiana são transfigurados em poemas que sugerem uma preocupação etnográfica de escrever e demonstrar o outro. Com relação à fundamentação teórica sobre a etnografia, os estudos de Susan Sontag (1987) e James Clifford (2002) foram utilizados. Com respeito à dimensão transversal da poesia, as reflexões de Octavio Paz $(1946 ; 1976)$ e de Alfredo Bosi (2006) também são consideradas. Finalmente, este artigo também pretende reconhecer a importância de Cecilia Meireles no panorama literário universal, pois por meio da leitura de seus escritos de viagens, é perceptivel que sua voz poética ecoa a trajetória da consciência humana.

Palavras-chave: Etnografia. Poemas Escritos na Índia. Cecilia Meireles.

Abstract: This article aims to perform an ethnographic reading of two poems entitled, "Multidão" and "Pobreza", present in the book Poems written in India (1961) belonging to the Brazilian poet Cecilia Meireles. When considering the importance of understanding, looking at and giving a voice to the other in the contexts in which egocentrism prevails, the ethnographic endeavor assumes itself as an unavoidable possibility. Indeed, the writing of displacement in poetic structure offers different versions and possibilities for understanding the foreign universe, since the literary language is plurisignificant. On this aspect, different characters from Indian culture are transfigured into poems that suggest an ethnographic concern to write and demonstrate the other. Regarding the theoretical foundation on ethnography, the studies of Susan Sontag (1987) and James Clifford (2002) were used. With regard to the transversal dimension of poetry, the thoughts of Octavio Paz (1946; 1976) and Alfredo Bosi (2006) were also considered. Finally, this article also intends to recognize the importance of Cecilia Meireles in the universal literary panorama, because through the reading of her travel writings, it is noticeable that her poetic voice echoes the trajectory of human consciousness. Keywords: Ethnography. Poems Written in India. Cecilia Meireles.

\section{(c) (1)}




\section{Introdução}

O presente artigo busca sugerir uma leitura etnográfica do livro intitulado Poemas escritos na Índia (1961), a partir da análise dos poemas "Multidão" e "Pobreza". É importante ter em vista que a obra ceciliana propicia novos olhares sobre a cultura e as subjetividades indianas, por meio da linguagem e das formas poéticas. Os poemas "Os cavalinhos de Delhi", "Passeio", "Santidade", "Família Hindu"e "Canto aos bordadores de Cachemir" constituem exemplos da reapresentação das particularidades culturais e espirituais que percorrem as paisagens e compõem as personalidades indianas.

Com efeito, distintos personagens da cultura indiana são transfigurados em poemas que transmitem uma preocupação de inscrever, entender e demonstrar as nuances dessa alteridade indiana, tão complexa aos olhos ocidentais. Apesar de vir do Ocidente, Cecilia Meireles, ao adotar uma postura de viajante, constrói um eu lírico determinado e atento aos aspectos culturais, sociais, estéticos, naturais e espirituais dessa outridade. E, sendo assim, é tentador reconhecer um lampejo etnográfico na poética ceciliana, elaborada a partir da presença, em território indiano, por dois aspectos: a construção de imagens que pretendem exibir e ressignificar o outro, quando a linguagem e a memória já não são suficientes; e, a consequente e potencial reconfiguração subjetiva (AIUB, 2014), por meio de ensinamentos que podem nos invadir de outro lugar, e, graças à transversalidade poética (BOSI, 2010), podem chegar até nós, os ocidentais e modernos.

Com relação à fundamentação teórica, os estudos de Susan Sontag (1987). François Dosse (1993) e James Clifford (2002) foram e são necessários à compreensão da escrita proveniente do deslocamento, em que o "eu" tenta se aproximar e se apropriar do outro, em termos científicos e estéticos. Ademais, é importante esclarecer que essa apropriação do outro, em termos da nova etnografia, não pode ser colonizadora, porém, geradora de vozes, percepções e autopercepções: uma verdadeira "provincialização" do conhecimento.

A metodologia se constitui pela análise dos textos à luz das principais teorias e reflexões suscitadas, com a finalidade de perceber como se escreve e se constrói o outro poeticamente e. por conseguinte, perceber os efeitos do entrelugar no sujeito que escreve. Como seria inviável analisar todos os poemas presentes no livro, devido à extensão do artigo, foram selecionados os poemas "Multidão" e "Pobreza" para compor o corpus. Finalmente, esse trabalho também pretende reconhecer a importância de Cecilia Meireles ao panorama literário universal, pois por meio da leitura de seus escritos de viagens, é perceptivel que sua voz poética ecoa a trajetória da consciência humana.

\section{A etnografia como escrita do outro: uma discussão abreviada}

Cecilia Benevides de Carvalho Meireles nasceu em 1901 na cidade do Rio de Janeiro. A trajetória existencial da poetisa foi marcada pela perda de seus familiares desde a infância: morreu-lhe o pai três meses antes do nascimento dela e, após três anos, perdeu a mãe, sendo criada pela avó materna açoriana. Desde muito cedo, Cecilia Meireles apresentou fascínio pela descoberta e afinidade com a imaginação, talvez, por ter como companhia a solidão na especulação dos mundos infantis, conforme entrevista cedida ao jornalista Pedro Bloch em maio de 1964:

Em pequena (eu era uma menina secreta, quieta, olhando muito as coisas, sonhando) tive tremenda emoção quando descobri as cores em estado de pureza, sentada num tapete persa. Caminhava por dentro das cores e inventava o meu mundo. Depois, ao olhar o chão, a madeira, analisava os veios e via florestas e lendas. Do mesmo jeito que via cores e florestas, depois olhei gente. Há quem pense que meu isolamento, meu modo de estar só (quem sabe se é porque descendo de gente da Ilha de São Miguel em que até se namora de uma ilha pra outra?), é distância quando, na realidade, é a minha maneira de me deslumbrar com as pessoas, analisar seus veios, suas florestas (MEIRELES,1964, n. 630). 
Além disso, também é oportuno distinguir nas palavras da escritora uma tendência para o exercício "olhar gente", ou seja, de se permitir o deslumbre ocasionado pela atenção e dedicação às tonalidades do mundo exterior, do terreno estrangeiro. Essa vocação da poetisa se justificou a partir de inúmeras viagens realizadas para distintos lugares: Portugal, Argentina, Holanda, Israel, Grécia, entre outros. De fato, todos esses deslocamentos proporcionaram experiências transformadoras na vida da escritora viciada em gostar de gente ${ }^{2}$. Contudo, houve uma viagem que se destacou entre todas outras realizadas até então: trata-se da viagem à Índia em 1953. ${ }^{3}$

Antes de percorrer os sentidos da viagem, a qual originou os Poemas escritos na Índia (1961) ${ }^{4}$. é importante considerar a esclarecedora distinção entre turismo e viagem. Para Cecilia, o turista é uma criatura feliz, preocupada apenas com a fotografia, o exótico e com suas poucas palavras mal faladas em idioma estrangeiro; já o viajante, é menos feliz, por ser vagaroso, afetado e profundamente interessado em abstrair o lugar, as pessoas e a experiência da viagem (MEIRELES, 2003). É curioso perceber que tal distinção também foi tema para a reflexão do também poeta, Michel Leiris, que ao ser impactado pela missão de Dakar-Djibouti, escreveu L'Abyssinie intime (1935), no qual se encontrava o já citado paralelo:

De acordo com ele, o modo como se viajava costumava alterar sobremaneira a percepção que se poderia ter de um lugar ou de um povo. Viajantes turistas, por exemplo - que deveriam ser, ainda segundo ele, "soberanos flaneurs", mas que, frequentemente, não passavam "de vulgares pessoas apressadas" - jamais conseguiriam estabelecer uma relação de intimidade com as regiões pelas quais transitavam. Uma viagem verda- deira, portanto, não deveria seguir horários, calendário nem mesmo itinerário configurando-se simplesmente como uma partida à aventura (THEOPHILO, 2015, p. 204, grifo da autora).

Em sintese, o turismo pode ser concebido como assintomático e superficial, já a viagem pode ser entendida como algo desestabilizador, incerto e profundo. Apesar de definir a viagem como "o alongamento do horizonte humano"5, Cecilia Meireles não participou de missões ou realizou notórios estudos etnográficos, como o seu colega de ofício, o já mencionado poeta francês, Michel Leiris, ${ }^{6}$ de maneira que, seria imprudente atribuir um estatuto científico de etnografia aos textos escritos na Índia. Entretanto, é plausivel explorar, em seus poemas, uma disposição em entender, traduzir e poetizar o estrangeiro, por meio de imagens, palavras e sons que tangenciam o outro em uma maneira de apropriação poética.

Sobre essa disposição pelo diferente, Susan Sontag afirma que:

A moderna sensibilidade se movimenta entre dois impulsos aparentemente contraditórios, mas em realidade relacionados: a rendição ao exótico, ao estranho, ao outro; e a domesticação do exótico, principalmente através da ciência (SONTAG, 1987, p. 86-87).

A domesticação do exótico institui a invenção do outro, como o outro inferior, vazio, que precisa se adequar ao modelo central de superioridade e de progresso.7 A rendição ao outro, porém, pode se caracterizar pela consciência de que o outro está além do nosso entendimento: nossa interpretação é parcelada, à proporção que nossos questionamentos são insuficientes, então,

\footnotetext{
2 "Meu vício é gostar de gente. Você acha que isso tem cura? Tenho tal amor pela criatura humana, em profundidade, que deve ser doença" (MEIRELES,1964, n. 630).

3 Sobre a İndia, a autora afirma: "I...] Na İndia foi onde me senti mais dentro de meu mundo interior. As canções de Tagora, que tanta gente canta como folclore, tudo na Índia me dá uma sensação de levitar. "[...] Quanto a Portugal, basta dizer que minha avó falava como Camões. Foi ela quem me chamou a atenção para a Índia, o Oriente: "Cata, cata, que é viagem da Índia", dizia ela, em linguagem náutica, creio, quando tinha pressa de algo, chá-da-İndia, narrativas, passado, tudo me levava, ao mesmo tempo à Índia e a Portugal" (MEIRELES,1964, n. 630).

4 Tomo por base a edição inicial da obra, realizada no Rio de Janeiro, em 1961.

5 "Cada lugar aonde chego é uma surpresa e uma maneira diferente de ver os homens e coisas. Viajar para mim nunca foi turismo. Jamais tirei fotografia de país exótico. Viagem é alongamento de horizonte humano" (MEIRELES,1964, n. 630).

6 Sobre as pesquisas etnográficas de Michel Leiris, indico a leitura do artigo de Theophilo (2015).

7 Sobre esse aspecto, tomo por base os estudos de Subirats (1994) e O'Gorman (2003) sobre a invenção domesticadora dos indigenas americanos nas viagens que buscaram desbravar o "Novo Mundo".
} 
é necessário render-se à falta, ao inalcançável dos orientais, entendidos como o universo estrangeiro a ser desvendado, o que, aliás, configura uma tarefa minuciosa aos ocidentais, compreendidos como investigadores de uma cultura alheia. ${ }^{8}$

Ainda em relação à rendição ao outro, ao discutir sobre o papel do antropólogo, baseando-se na figura de Claude Lévi-Strauss, François Dosse (1993, p. 153) identificou a "quebra do molde hierárquico de uma sociedade ocidental que se apresentava como modelo a ser seguido pelo resto do mundo" ocasionada pelo o que ele chamou de "irredutibilidade da diferença". E, é a partir da diferença que o contato com o outro pode proporcionar um conhecimento sobre nós mesmos, como se oferecesse uma outra estratégia para montarmos o nosso próprio quebra-cabeça. ${ }^{9}$ Essa, aliás, seria a principal consequência da "vertigem intelectual" (SONTAG, 1987, p. 86), ocasionada pelas abruptas transformações históricas, o que leva as sensibilidades modernas a buscarem respostas a partir do contato com o outro.

\section{Entre a parcialidade e a curiosidade: a experiência do viajante em linhas poéticas}

Se considerássemos apenas o caráter factual e o estrutural da experiência etnográfica, os quais se preocupavam, apenas, com a elaboração de modelos a serem seguidos e a serem excluídos, poderíamos entendê-la como um intento histórico, objetivo e relativo. Entretanto, a partir das recentes perspectivas sobre o fazer etnográfico e o seu diálogo com a Literatura, é permitido construir retratos integrados, ${ }^{10}$ os quais lançam outras perspectivas sobre o outro mundo que já não é o mesmo que foi antes do encontro entre as realidades distintas: trata-se de uma terceira alternativa que surge do "escape", ou seja, do que se imagina entre os dois mundos.

A disposição em imagens ou imaginação pode ser entendida como "[...] um ato mágico. É um encantamento destinado a fazer aparecer o objeto em que estamos pensando, a coisa que desejamos, de modo a podermos tomar posse delas" (SARTRE, 1996, p. 236). Novamente, a resolução se oferece em imagens que permitem o deslumbre, a ressurreição do outro instante; e, a consequente ilusão de que possuímos o que vemos: eis o movimento mágico, ou, em outras palavras, a apropriação poética e imaginária que se manifesta por uma atitude de rendição ao outro, com a finalidade de que esse outro possa habitar em nós, através de imagens e canções. Essa atitude, aliás, estabelece uma alternativa para a "etnografia recente" e uma sedução para a atividade poética, pois:

A poesia lírica representa o geral verossímil, o valor extensivel ao conjunto dos homens, sua semelhança para com os outros e a representação do humano em geral, verossímil e não verdadeiro, artístico e não real, modelo e não natureza, falar imaginário e não comunicação histórica (POZUELO, 1997, p. 260, tradução nossa). ${ }^{11}$

Esse falar imaginário caracteriza o primeiro poema do livro escrito a partir da viagem de Cecilia Meireles à Índia, se trata do poema "Multidão", que em cinco estrofes elabora um retrato integrado dos transeuntes que caminham destemidos, rumo ao desconhecido, o que constitui motivo de curiosidade ao eu lírico, que também pode ser entendido como a "automodelagem" do viajante curioso e atento. Lemos, então, Cecilia Meireles (2013, p. 271):

Aonde vão esses passos pressurosos, Bhai?

A que encontro? a que chamado?

em que lugar? por que motivo?

\footnotetext{
8 Essa perspectiva horizontal caracteriza a nova etnografia: "I...] a confiança evolucionista começou a ratear, e uma nova concepção etnográfica de cultura tornou-se possivel. A palavra começou a ser usada no plural, sugerindo um mundo com modos de vida separados, distintos e igualmente significativos" (CLIFFORD, 2002, p. 101).

9 "[...] esse outro pode instruir-nos a respeito de nós próprios, retroceder para nos transformar enquanto fragmento significante do universal humano" (DOSSE, 1993, p. 153).

10 Sobre esse aspecto, é importante retomar a importância da memória na tarefa do etnógrafo, em seus momentos posteriores de tradução, análise e interpretação dos dados obtidos, construindo, assim, um retrato posterior do outro observado: "[...] Em última análise, o etnógrafo sempre vai embora, levando com ele textos para posterior interpretação (e entre estes "textos" que são levados podemos incluir as memórias - eventos padronizados, simplificados, retirados do contexto imediato para serem interpretados numa reconstrução e num retrato posteriores" (CLIFFORD, 2002, p. 40).
} 
É pertinente observar também a utilização recorrente do vocativo "Bhai" em toda a extensão do poema, como aquele a quem o eu lírico destina as suas inquietações. "Bhai" é uma palavra que significa "irmão", o que dispõe um caráter de fraternidade, necessário à toda experiência etnográfica que se pretende horizontal e dialógica. Além disso, o eu lírico como uma representação do viajante, entendido como um observador atento, paira no próprio impasse do entre-lugar, pois se encontra em suspense: entre o encaixe nunca satisfatório de duas culturas distintas, já que sempre há algo por descobrir, por alcançar:

Bhai, nós, que parecemos parados, por acaso estaremos também, sem o sentirmos,

correndo, correndo assim, Bhai, para tão longe,

sem querermos, sem sabermos para onde, como água, nuvem, fogo?

(MEIRELES, 2013, p. 271)

Como alternativa ao embaraço de se situar entre o movimento (a caminhada) e a inércia perplexa daquele que observa e reflete, o eu lírico supõe a participação não consciente desse mesmo movimento, orientado à adesão comunitária de um chamado de longe e, assim, tenta se colocar no lugar do outro, a fim de melhor entendê-lo. Entretanto, esse movimento apenas pode se manifestar em projeção, pois o viajante, aos olhos da multidão é o estrangeiro e, assim, carrega o peso da falta, da inadequação e da inevitável diferença, por mais que esteja disposto a entender os motivos e acompanhar os passos dessa multidão: o viajante será atravessado e ultrapassado por ela, pois seu conhecimento sobre essa cultura é parcial, é apreendido e não inerente. Daí, a necessidade de projetar, de imaginar o outro e de se imaginar como outro, por meio de aproximações tateantes, as quais não possibilitam certezas absolutas. E, enfim, como a experiência do viajante é parcial e não absoluta, especialmente, por ser pautada no acaso e na inadequação, os fatos e percepções, assim como as poses assumidas, "desabam pelas muralhas do tempo", sugerindo que não somente as iniciativas históricas são invulneráveis à imperatividade dos tempos, mas também que a própria condição humana é efêmera e transitória, de maneira semelhante à caminhada apressada dessa multidão estrangeira. Finalmente, é precisamente nesse aspecto de fragilidade da existência humana que o viajante atônito e a ávida multidão estrangeira se encontram, mesmo que pareçam se desencontrar entre passos frente à imobilidade: somos todos fraternos nessa caminhada rumo às incertezas da fugaz vivência humana. $E$, dessa forma, a voz lírica sugere o exercício de empatia, importante tanto para a atividade poética, quanto para a iniciativa etnográfica de entender, imaginar e se apropriar do outro, à proporção que também realiza uma reflexão sobre si e desvenda semelhanças em meio às diferenças.

Bhai, quem nos espera, quem nos receberá,

quem tem pena de nós, cegos, absurdos, erráticos, a desabarmos pelas muralhas do tempo? (MEIRELES, 2013, p. 271)

Ainda sobre a projeção do outro, com a finalidade de elaborar um retrato integrado, o segundo poema analisado é exemplar. Tratase de uma descrição poética de um tipo social negligenciado: o mendigo. "Pobreza" é o título do poema que condensa, em imagens, a percepção do eu lírico, como um observador atento a especular sobre o morador de rua oriental. Lemos, então, Cecilia Meireles (2013, p. 272):

Não descera de coluna ou pórtico, apesar de tão velho; nem era de pedra, assim áspero de rugas; nem de ferro, embora tão negro.

Não era uma escultura, ainda que tão nítido, seco, modelado em fundas pregas de pó. 
Em primeiro lugar, o eu lírico elabora o perfil físico desse mendigo: as marcas do tempo, mas que também sugerem as marcas da indiferença social, ao parecer confundi-lo, primeiramente, com uma pedra e depois com uma escultura, ou seja, com um objeto banal (as pedras que se encontram nas estradas) ou com um artigo de decoração de um cenário social (escultura); de uma forma ou de outra, o mendigo é caracterizado como um elemento acessório ao funcionamento da sociedade. Porém, representando um observador atencioso por conhecer um pouco mais das essências humanas, o eu lírico vai além, tentando reconhecer pelo o que o mendigo não é, já que sua existência social está fadada ao não ser, o que ele poderia ser sob outra perspectiva, pois na verdade a pobreza é que pode ser inventada e atribuida, uma vez que o morador de rua é um homem vivo, existente, apesar de ser uma imóvel testemunha das desigualdades sociais, dado que é vítima de descaso social, o que também é indicativo de seu silenciamento (voz imperceptivel), ainda que cante, faça suas preces e súplicas, de modo semelhante a toda criatura humana fadada à inescapável angústia da vida. Outrossim, é importante notar o jogo existente entre imagem e som nas linhas poéticas do eu lírico ceciliano, com a finalidade de elaborar a ideia de que apesar do silêncio, a imagem do esmoleiro é estrondosa e concreta como uma escultura que se apropria do mundo com olhos de opala, o que, mais uma vez, sugere a humanização e a subjetividade do mendicante, mesmo que, em um primeiro momento, em um primeiro lance de vista cansada, o morador de rua pareça ser apenas uma peça substituivel do cenário:

Não era inventado, sonhado,

mas vivo, existente,

imóvel testemunha.

Sua voz quase imperceptivel

parecia cantar - parecia rezar

e apenas suplicava.

E tinha o mundo em seus olhos de opala.

(MEIRELES, 2013, p. 272)
O eu lírico, entendido como um observador vigilante, amplia, um pouco, seu horizonte de visão e focaliza as pessoas também na cena, as quais por contradição e ironia nada têm a oferecer, como se estivessem com as mãos e com os olhos fechados, de modo a efetivar a sincronia com o descaso e a negligência vigentes. Por outro lado, o mendigo se encontra de mãos abertas a oferecer bênçãos, longevidade e imortalidade, elementos, aliás, das pessoas que apenas seguem os caminhos sem contemplá-lo, ou, simplesmente, fingindo que ele não existe. Logo, temos, novamente, a ironia dessa cena descrita em linhas poéticas, sugerindo que a pobreza é um conceito relativo, inventado e atribuido, uma vez que, sob outra perspectiva, o esmoleiro seria mais afortunado e generoso do que as pessoas que simplesmente o ignoram. Esse retrato do mendigo indiano é desestabilizador, polêmico aos olhos alheios, porque sugere as carências daqueles que se consideram os modelos de prosperidade de uma existência social. Sob a perspectiva inusitada do eu lírico, há uma subversão de valores: a abastança material pode ser considerada uma privação, porque ao prenderse às limitações terrenas e às necessidades materiais, os transeuntes não contemplavam a vida e, assim, não se assenhoravam desta:

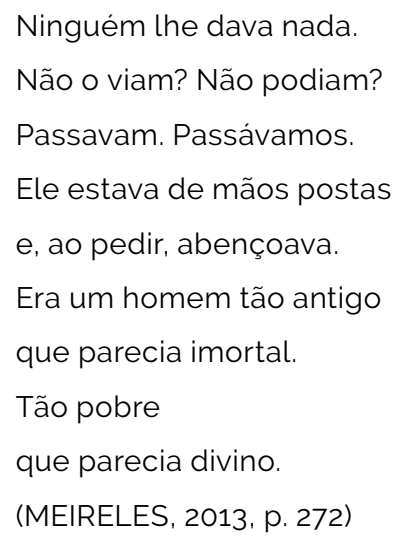

Sendo assim, o mendigo, retratado pelo eu lírico, se constitui como uma essência livre, justamente, porque vive segundo suas próprias normas e está "desencaixado" do padrão de vida de progresso e de acúmulo de riquezas, tão buscado pelos indivíduos modernos. Portanto, é através de 
uma ironia que o mendigo, por assenhorar-se de sua existência velada, alcança um aspecto de superioridade frente àqueles que o ignoram. Finalmente, esse retrato de um tipo social indiano foi elaborado em forma poética, a partir de uma observação atenta, o que possibilita a regeneração do olhar e a ressignificação de perspectivas, experiências, aliás, pertinentes tanto para a tarefa etnográfica quanto para a iniciativa poética.

\section{Considerações finais}

Após as breves reflexões realizadas, o presente trabalho buscou encontrar no livro Poemas escritos na Índia (1961), de Cecilia Meireles, um viés etnográfico, a partir da análise de dois poemas e de considerações teóricas. O modo particular de ver o outro, de apropriar-se dele e de fornecer-lhe uma outra perspectiva, em construção poética, se constitui como a principal justificativa: a etnografia e a poesia caminham juntas na elaboração de retratos integrados, pois poetas e etnógrafos precisam salvar almas, já que além de construtores de espelhos, também são modeladores do espírito.

Com relação aos artistas e àqueles que não se nomeiam artistas, mas que ainda assim, se portam como construtores de espelhos e de subjetividades, Michel Leiris sugere a seguinte missão:

\begin{abstract}
Incorporar a morte à vida, torná-la de certa maneira voluptuosa, tal deve ser a atividade dos construtores de espelhos, quero dizer: de todos aqueles que tem por propósito mais urgente agenciar alguns desses fatos que podemos tomar por lugares onde o homem tangencia o mundo e a si mesmo, que portanto nos alçam ao nivel de uma plenitude portadora de sua própria tortura e sua própria derrisão (LEIRIS, 2001, p. 75).
\end{abstract}

Logo, poetas e etnógrafos se aproximam mais uma vez ao optarem por agenciar o encontro tangencial entre o homem, o mundo e ele mesmo, por meio de linguagens e quando essas são insuficientes, através de imagens. Em segundo lugar, não esqueçamos da importância conferida à imagem poética para Octavio Paz, especialmente, à capacidade imagética de harmonizar os contrários e, assim, conseguir dizer o indizivel: "[...] há que retornar à linguagem para ver como a imagem pode dizer o que, por natureza, a linguagem parece incapaz de dizer" (PAZ, 1946, p. 44).

Retomando o papel do etnógrafo e do poeta de construir espelhos, no qual a imagem é elemento fundamental, as afirmações do teórico mexicano se encontram com as de Bradley (1954, p. 100): o sentido da imagem especular é excepcionalmente norteador, assim como as imagens poéticas: "mostrar ao mundo o que ele é... e indicar o que deverá ser" (tradução nossa). E, assim disponibilizar outros caminhos para a compreensão do próprio e do alheio, já que é também por meio da imagem:

A imagem transmuta o homem e converte-o por sua vez em imagem, isto é. em espaço onde os contrários se fundem. E o próprio homem, desgarrado desde o nascer, reconcilia-se consigo quando se faz imagem, quando se faz outro (PAZ, 1976, p. 50 grifo do autor).

Finalmente, é importante ter o discernimento de que a apreensão do universo humano se constitui por uma reconciliação de contrários, ou seja, através de um encontro e de uma reflexão sobre o outro. Sendo assim, mais uma vez a etnografia e a poesia se constituem, ressalvados os seus meios científicos e estéticos respectivamente, como um constante exercicio de empatia e de compreensão tão caros ao mundo moderno.

\section{Referências}

AIUB, G. F. O sujeito entre linguas materna e estrangeira: lugar de interferências, historicidades e reverberações. Curitiba: Appris, 2004. p. 15-22.

BOSI, A. O ser e o tempo da poesia. 8. ed. São Paulo: Companhia das Letras, 2000.

BRADLEY, Sister Ritamary. Backgrounds of the Title Speculum in Mediaeval Literature. Speculum: a journal of mediaeval studies, Massachusetts, Cambridge, 1954. https://doi.org/10.2307/2853870

CLIFFORD, J. A experiência etnográfica: antropologia e Literatura no século XX. Rio de Janeiro: Ed. UFRJ, 2002.

DOSSE, F. História do estruturalismo. Campinas: UNICAMP, 1993

LEIRIS, M. O espelho da Tauromaquia. São Paulo: Cosac Naify, 2001. 
MEIRELES, C. Roma, turistas e viajantes. In: MEIRE-

LES, C. Melhores crônicas: Cecilia Meireles. Seleção e prefácio: Leodegário A. de Azevedo Filho. São Paulo: Global, 2003. p. 256-260. (Melhores Crônicas).

MEIRELES, C. Poemas escritos na Índia. In: Antologia Poética. São Paulo: Global, 2013.

MEIRELES, C. A última entrevista de Cecilia Meireles. In: LEITE, C.W. (org.). Revista Bula. Disponivel em: http://www.revistabula.com/496-a-ultima-entrevista-de-cecilia-meireles/. Acesso em: 05 jan. 2018.

O'GORMAN, E. A invenção da América: reflexão a respeito da estrutura histórica do Novo Mundo e do sentido do seu devir. São Paulo: UNESP, 1992.

PAZ, O. Signos em rotação. Tradução de Sebastião Uchoa Leite. 2. ed. São Paulo: Perspectiva, 1976.

POZUELO, J. M. Lírica y Ficción. In: DOMINGUEZ, A. G. (org.). Teorias de la ficción literaria. Madrid: Arcos, 1997.

SONTAG, Susan. O antropólogo como herói. In: SONTAG, Susan. Contra a interpretação. Porto Alegre: L\&PM, 1987.

SUBIRATS, Eduardo. El continente vacio: la conquista del nuevo mundo y la consciencia moderna. México: Siglo veintiuno editores, 1994.

TEOPHILO, G. M. Construtor de espelhos: etnografia, literatura e mistica na obra de Michel Leiris (França, 1930-1960). Revistas Esboços, Florianópolis, v. 22, n. 33, p.198-216, dez. 2015. https://doi.org/10.5007/ 2175-7976.2014V22n33p198

\section{Endereço para correspondência}

Amanda Moury Fernandes Bioni

Universidade Federal de Pernambuco

Centro de Artes e Comunicação (CAC) - Sala do PPGL.

Av. da Arquitetura, S/n - Campos Universitários.

Bairro: Cidade Universitária. CEP: 50740-550.

Recife, PE, Brasil. 